Article

\title{
Exploring the Role of Malaysian Student's Intrapreneurial Self-Capital in the Relationship between Satisfaction with Life, Academic Performance, and Flourishing
}

\author{
Chua Bee Seok ${ }^{1}$, Pan Lee Ching ${ }^{1}$ and Rosnah Ismail ${ }^{2, *}$ \\ 1 Faculty of Psychology and Education, Universiti Malaysia Sabah, Kota Kinabalu 88400, Malaysia; \\ chuabs@ums.edu.my (C.B.S.); plc_81@hotmail.com (P.L.C.) \\ 2 Department of Psychology, Faculty of Allied Health Sciences, University of Cyberjaya, \\ Cyberjaya 63000, Malaysia \\ * Correspondence: rosnahismail@gmail.com
}

Received: 21 November 2019; Accepted: 10 January 2020; Published: 13 January 2020

\begin{abstract}
Intrapreneurial self-capital is the construct coined by Di Fabio as a core of individual resources used to cope with career and life construction challenges. In this study, we used the model of Individual Differences in Evaluating Life Satisfaction (IDELS) to examine the mediating role of intrapreneurial self-capital in the relationship between life satisfaction and flourishing among Malaysian undergraduate students. The Intrapreneurial Self-Capital Scale (ISCS), Satisfaction with Life Scale (SWLS), and Flourishing Scale were administered to 665 undergraduate students from one of the public universities in Kota Kinabalu, Sabah, Malaysia. The results reported a significant direct effect of student satisfaction with life to flourishing. A significant path coefficient was also found from satisfaction with life and student academic performance to intrapreneurial self-concept providing the support that student satisfaction with life and academic performance has a positive effect on their intrapreneurial self-concept. The coefficients from intrapreneurial self-concept to flourishing was also significant. This provides initial support that an intrapreneurial self-concept may have a positive mediating effect on the relationship between satisfaction with life, academic performance, and flourishing. We found that the indirect effects of satisfaction with life and academic performance on flourishing through intrapreneurial self-concept were significant. These results provided further support for the mediating effect of intrapreneurial self-concept. The analysis also that revealed satisfaction with life was significantly and positively related to flourishing. However, the finding showed no significant direct effect of student academic performance on flourishing.
\end{abstract}

Keywords: intrapreneurial self-capital; satisfaction with life; academic performance; flourishing

\section{Introduction}

The global change affects the employment content, and thus organizations are most likely to encounter management conflict [1]. Individuals' job security is at risk of the restructuring of job content [2], if they lack competence and innovation of their working style. Malaysia is no exemption from this issue, and quite a number of big corporations that used to dominate the local economic downsizing due to uncertainty in the economic world. Organizations need a preventive measure to tackle these challenges, otherwise they are prone to deal with human capital complexity.

Undergraduates are vulnerable to stepping into the professional world. They venture into the non-school environment, expecting to work competently. Scholars question their flourishing towards life and career as they feel uncertain about how far their academic qualifications could help them 
shape their future after the completed studies [3]. Thus, the undergraduates require help in terms transitioning from student life to employment [4]. Undergraduates, especially in Eastern countries, depend on their academic performance to determine their future especially career [5]. Therefore, delivering good scores is the road to success. It is a question whether they are well prepared in terms of psychological well-being to venture into a new environment in life. A suggestion about a training focusing on intrapreneurial self-capital (ISC) is a promising resource to face the challenges of the 21st century [6].

Intrapreneurial self-capital [7], a new higher-order psychological construct that is claimed to be an equally essential value that needs to be nurtured, because it is a protective factor for individuals [8]. ISC offers personal resources for coping with continuing societal change and transitions because it promotes well-being and flourishing, as well as amenable to intervention [9]. Therefore identifying how undergraduates perceive themselves in terms of their satisfaction with life and flourishing through intrapreneurial self-capital is important. Additionally, performing a study among the youth at the university level is an advantage because this could help undergraduates to prepare in the psychological aspect before entering the job market [7].

Small studies could relate satisfaction with life, academic performance, and flourishing with intrapreneurial self-capital. Some studies showed that intrapreneurial self-capital is linked with satisfaction with life and flourishing among Italian university students [9]. In addition, there is a positive relationship between academic performance and intrapreneurial self-capital [7].

This paper led to the following research questions: firstly, whether satisfaction with life and academic performance has a direct relationship with flourishing, and secondly, whether intrapreneurial self-capital could intervene in the direct relationships. Therefore, this study was aimed to investigate the relationship between satisfaction with life, academic performance, and flourishing. Then, intrapreneurial self-capital was used to find out whether it mediates these relationships.

\section{Satisfaction with Life, Academic Performance, and Flourishing}

Flourishing is an essential value because it is about positive well-being, good life experience, feeling well, and the ability to function effectively [10]. Well-being refers to perception in relationships, self-esteem, purpose, and optimism [11]. Possessing this value at the university level would help undergraduates to thrive for success in life and their career. Individuals with a high satisfaction with life have positive well-being in terms of health, social skills, and energy [12]. Acquiring good satisfaction in life has a positive link to social relationships [12]. Past studies found satisfaction with life has a positive relationship with flourishing components such as well-being [13], optimism [14], and self-esteem [15].

Undergraduates that have higher life satisfaction have a better academic performance, less academic stress, and are more goal-oriented compared to those with average or lower life satisfaction [16,17]. The finding suggested that acquiring a positive effect on life and feeling happy to produces a good academic performance and also increases personal values. Undergraduates are prone to flourish when they successfully posit a place at the university. Acquiring better education is symbolic of individuals' success, and this is widely accepted in Asian culture [18]. In a Filipino setting with university students, it was found that there is a positive connection between academic performance and flourishing [17]. The study also claimed that the students' social skills were enhanced, as undergraduates that excel in academics are expected to communicate more with lecturers and team members. However, a study in Malaysia revealed that life satisfaction among second and third-year students in public universities has no significant relationship with the academic performance [5].

According to the above factors, satisfaction with life that promotes feeling good about oneself is prone to flourish and overcome obstacles in career and life. Feeling satisfied with life creates positive psychology that helps to excel in life. Although flourishing has attracted scholars' attention in a positive psychology context [19], only small studies have explored the relationship between satisfaction 
with life, academic performance, and flourishing in the undergraduate context. Based on past studies arguments, this study predicted the following hypotheses:

Hypothesis 1: Satisfaction with life significantly influences flourishing.

Hypothesis 2: Academic performance significantly influences flourishing.

\section{Intrapreneurial Self-Capital}

Intrapreneurial self-capital is a core of personal resources that helps individuals to cope with constraints when they experience changes and challenges in career and life [7,20]. ISC [7] is a higher-order construct containing seven sub-constructs: core self-evaluation, hardiness, creative self-efficacy, resilience, goal mastery, decisiveness, and vigilance. Core self-evaluation is about positive psychological evaluation including self-esteem, self-efficacy, locus of control, and being optimistic (e.g., Item 1, Sometimes when I fail I, feel valueless) [21]. Hardiness shows the ability to resist a difficult situation through its three sub-dimensions, commitment, control, and challenge (e.g., Item 5, Studying committed to the maximum really pays off in the end). Being committed to difficulty in life leads individuals to engage in life aspects, identify goals, and priorities. The control allows an individual to influence life events according to what they perceive. Challenge refers to the flexibility to face new and unexpected events. Creative self-efficacy is the ability to generate new ideas to solve the problem (e.g., Item 14, I am able to solve problems creatively) [22]. Resilience allows individuals to cope with adversity and use adaptive ways to resist (e.g., Item 17, I am able to achieve objectives despite obstacles) [23]. Goal mastery refers an ability to develop and discover potential skills for optimum performance (e.g., Item 20, One of my goals is to acquire new skills) [24]. Possessing decisiveness is the ability to make decisions timely in any life events (e.g., Item 23, After I chose or decided something I often think that I chose wrongly) [25]. Vigilance enables an individual to make a decision wisely after considering several sources and developing a strategic plan to solve the problem (e.g., Item 26, When I must make a decision, I like to stop and consider all possible options) [26].

Intrapreneurial self-capital is a function that enables individuals to sustain in a highly competitive environment that can promote health and well-being, including flourishing [27]. This is a new construct; small studies could affirm the relationship of intrapreneurial self-capital with satisfaction with life and flourishing. A study found that intrapreneurial self-capital has a connection to satisfaction with life and flourishing among Italian workers [20] and university students [9]. These results suggested that individuals that have high intrapreneurial self-capital increase their flourishing in career and life too. Satisfaction with life also influences the level of their intrapreneurial self-capital in dealing with hardship in both their career and life [20]. This makes sense, as securing a desired standard life betters an individual's mood and increasse self-esteem. Such a situation could help individuals act confidently when encountering difficulties. In the long run, they are prone to success in profession and life. In more recent studies, it showed that intrapreneurial self-capital was significantly associated with flourishing among Spanish employees [28]. Past studies are widely performed in the Western setting, but it is proven that the intrapreneurial self-capital is reliable to be applied among Malaysian youth, especially the undergraduates [29].

To generate good academic performance is a difficult task because undergraduates, especially in Eastern countries like Malaysia, emphasize examination status to get a good career and fulfill their family's values [5]. Therefore, they strive for success through good scores. Dealing with the hardship environment with positive personal resources like intrapreneurial self-capital would help undergraduates to achieve from academic to desire profession. Nevertheless, small studies could affirm the notion. Consequently, this study hypothesized like below:

Hypothesis 3: Intrapreneurial self-capital mediates the relationship between satisfaction with life and flourishing. 
Hypothesis 4: Intrapreneurial self-capital mediates the relationship between academic performance and flourishing.

\section{Method}

\subsection{Participants}

Participants were 665 undergraduate students from one of the public universities in Kota Kinabalu, Sabah. They participated in the online study using a Google Docs Form after the related announcement, and the Google link was communicated to them by the researchers and lecturers. Thus, the participants involved in the current study were those who responded to the Google Docs Form online study. The students were in their second and third year of studies. Their ages ranged from 18 to 27 , with a mean age of 21.70 years $(\mathrm{SD}=2.23$ ). There were $32.0 \%$ second-year students and $67.9 \%$ third-year students. The sample consists of 435 (65.5\%) female students and 229 (34.5\%) male students. In terms of ethnic background, 27.4\% are Malay, 15.7\% Chinese, 4.1\% Indian, 16.1\% Kadazandusun, $11.6 \%$ Bajau, 3.3\% Malay Brunei, and 21.8\% indicated as "Other". There were 59.2\% Muslim students, $25.2 \%$ of students were Christian, 8.6\% were Buddhist, 3.5\% were Hindu and 3.6\% indicated "Other".

\subsection{Measurement}

The measurement used in the current study consists of three parts: demographic information, The Intrapreneurial Self-Capital Scale (ISCS) [7] in the Malaysian version [29], the Satisfaction with Life Scale (SWLS) [30], and The Flourishing Scale (FS) [11]. The demographic information includes gender, age, religion, ethnicity and respondents' year of study and academic performance.

The Intrapreneurial Self-Capital Scale (ISCS) was developed to measure intrapreneurial self-capital, a core of individual resources to manage career and life challenges. ISC is a higher-order construct and the ISCS consisted of 28 items with a 5-point Likert scale response format ( $1=$ strongly disagree, $2=$ disagree, $3=$ neither agree nor disagree, $4=$ agree, $5=$ strongly agree). The scale consisted of eight negative items (e.g., items $(1,2,3,7,12,13,23$, and 24.) which required the score to be reversed before proceeding for further analysis. The original ISCS is in Italian and via an English version supplied by the authors [29] had done the back-to-back translation into Bahasa Malaysia which was used in the current study. The internal consistency reliability of the original Italian version of ISCS was Cronbach's alpha coefficient $=0.84$ [7]. In the current study, the Malaysian version of ISCS also indicating good reliability (Cronbach's alpha coefficient $=0.83$ ).

The Satisfaction with Life Scale (SWLS) has been widely used as a measure of the life satisfaction component of subjective well-being. The SWLS consists of five items designed to measure global cognitive judgments of satisfaction with life. Participants' responses to each item of SWLS were scored using a seven-point Likert style response scale (from $1=$ strongly disagree to $7=$ strongly agree) to indicate respondents' degree of agreement or disagreement with each statement of the items. Higher scores indicate higher satisfaction with life. Cronbach's alpha coefficient for the SWLS was ranged from 0.79 to 0.89 [30], which indicates that the scale has high internal consistency. The SWLS was also found to have good test-retest correlations of 0.84 and 0.80 over a month interval. In the current study, the Cronbach's alpha coefficient for the SWLS was 0.74 .

The Flourishing Scale is a brief eight-item measure designed to describe important aspects of human functioning such as positive relationships, meaning, and purpose in life, self-esteem, and optimism. The scale provides a single psychological well-being score. In an earlier publication, the scale was called Psychological Well-being, however, to more accurately reflect the content, the scale was changed to flourishing as the content went beyond psychological well-being. Responses for the eight-item measure were given on seven-point scales ranging from $1=$ strongly disagree to $7=$ strongly agree to indicate respondents' degree of agreement or disagreement with each statement of the items. All items are phrased in a positive direction and high scores indicate that respondents view themselves in positive terms in important areas of functioning. The internal consistency for the Italian version of 
the Flourishing scale was Cronbach's alpha coefficient $=0.88$ [6], and the internal consistency for the Malaysian version of this Scale was Cronbach's alpha coefficient $=0.93$.

\subsection{Data Analysis}

Data of the study were analyzed using the IBM SPSS AMOS 23 Program. Structural Equation Modeling (SEM) was conducted to analyze the mediation process of independent variables (satisfaction with life and academic performance), mediator (intrapreneurial self-capital), or dependent variables (flourishing) of the current study. SEM was able to identify the total variance of endogenous latent variables (e.g., flourishing and intrapreneurial self-capital) that explained by the exogenous latent variables (satisfaction with life) in the current study model. The reliability of the instruments was assessed by examining its Cronbach's alpha, the internal consistency reliability.

\subsection{Results}

Table 1 shows the direct and indirect effect of the mediation test of satisfaction with life and academic performance on student flourishing through intrapreneurial self-capital among the students. It depicts the graphical demonstration of the paths of the model. The goodness-of-fit statistics of the overall model was fit to the data $(\mathrm{X} 2=1407.60, \mathrm{df}=621, \mathrm{pb}=0.01$, RMSEA $=0.06, \mathrm{CFI}=0.89)$. The results indicate a significant positive direct effect of satisfaction with life to student outcome of flourishing $(\beta=0.22, p<0.05)$. However, a non-significant path coefficient was found from academic performance to student flourishing $(\beta=-0.01, p>0.05)$.

Table 1. Mediation of the effect of satisfaction with life and academic performance on student flourishing through intrapreneurial self-capital.

\begin{tabular}{lcc}
\hline \multicolumn{1}{c}{ Direct Effect } & Estimate & $\boldsymbol{p}$-Value \\
\hline From Satisfaction with life to Flourishing & 0.22 & 0.000 \\
From Academic performance to Flourishing & -0.01 & 0.795 \\
From Intrapreneurial Self-Capital to Flourishing & 0.21 & 0.000 \\
From Satisfaction with life to Intrapreneurial Self-Capital (ISCS) & 0.41 & 0.000 \\
From Academic performance to Intrapreneurial Self-Capital (ISCS) & 0.10 & 0.005 \\
\hline Indirect effect & & \\
\hline From Satisfaction with life to Flourishing through ISCS & 0.09 & 0.003 \\
From Academic performance to Flourishing through ISCS & 0.02 & 0.004 \\
\hline
\end{tabular}

Findings revealed that significant path coefficients were found from satisfaction with life ( $\beta=0.21$, $p<0.05)$ and academic performance $(\beta=0.10, p<0.05)$ to intrapreneurial self-capital, the analysis providing support that satisfaction with life and academic performance have a positive effect on student intrapreneurial self-capital (refer to Table 1).

The result also showed that the coefficients from intrapreneurial self-capital to flourishing $(\beta=0.21$, $p<0.05)$, was significant. This finding provides initial support that intrapreneurial self-capital may have a positive mediating effect on the relationship between satisfaction with life and the student outcome of flourishing, and the relationship between academic performance and the student outcome of flourishing.

We also calculated the indirect effects of satisfaction with life and academic performance on student flourishing, to provide more evidence for the mediating role of intrapreneurial self-capital. As shown in Table 1, the result showed that the indirect effects of satisfaction with life (estimate $=0.09, p<0.05$ ) and academic performance (estimate $=0.02, p<0.05$ ) on student flourishing through intrapreneurial self-capital were significant. These results provided further support for the mediation effect of the intrapreneurial self-capital in these causal relationships. 


\section{Discussion}

This study was aimed to investigate the intrapreneurial self-capital role as a mediator in the relationship between satisfaction of life, academic performance, and flourishing. This study used data of public university students in Sabah, Malaysia. The finding showed satisfaction with life did influence the flourishing of the undergraduates. Experience satisfying and excellent life nourish their growth in terms of positive relationships, competency, and acquire a meaningful life [11]. The undergraduates in public university Sabah are aware that being a success in the society is to practice the value of flourishing. Living in a highly competitive society makes them urge for more flourishing in relationships. Being competent in activities that they feel passionate about nurtures their positive psychology too.

The finding revealed that satisfaction with life significantly influenced the flourishing. This study and past studies' findings [14] suggested that undergraduates that acquire a meaningful life are feeling optimistic about their life. The result also parallels with past studies [13,15].

The result contracted with past studies [17] as it demonstrated that academic performance has no significant influence on flourishing. This could be related to this study's prediction that intrapreneurial self-capital would mediate the academic performance and flourishing which is explained at the end of this section. This study managed to explain intrapreneurial self-capital influenced the flourishing. The result is aligned with past studies $[3,20]$. Being technology savvy, undergraduates are very competitive to follow the trend and they have high expectations of themselves too. Therefore, practice values like resilience and being creative in dealing with challenges and solving problems could warrant to achievements in career and life.

The finding further confirmed past studies [20] of which the satisfaction with life and intrapreneurial self-capital was connected. Similarly, with other studies [9], the undergraduates' intrapreneurial self-capital was influenced by their life satisfaction. That means, how they perceive their life satisfaction would determine their intrapreneurial self-capital, an essential values that help them to sustain changes (e.g., society, political, and economic) through personal resources [7]. The ability to sustain in a hardship environment through positive psychology is promising to achievement [20]. The finding showed that academic performance influenced intrapreneurial self-capital. That means the level of academic performance determines how undergraduates would cope with constraints in their life. This makes sense, because undergraduates work hard and constantly find solutions for all questions, especially Asian countries like Malaysia [5]. They do in-depth research to find answers. Such situations would shape their positive psychology including to be more resilient, committed, and optimistic to achieve good results.

The significant contribution of this paper is that intrapreneurial self-capital is found to fit as a mediator in the studied model. Thereby, intrapreneurial self-capital is a potential factor to intervene in the well-being of undergraduates. Results showed intrapreneurial self-capital mediated the relationship between satisfaction with life and flourishing. With the presence of intrapreneurial self-capital, undergraduates that are satisfied with their life can act more flourishing. Acquiring satisfying life improves undergraduates' resilience and, in turn, helps them develop a meaningful life and good capability for social interactions. Satisfaction with life increases undergraduates' high order thinking when it comes to problem-solving and delivering ideas. Such a situation helps them thrive for success. The intrapreneurial self-capital also mediates the relationship between academic performance and flourishing. The mediator is a function that increases undergraduates' flourishing when their academic performance is promising, this is in line with past studies [28]. Good examination scores deepen their knowledge and skills that help them evolve in a highly competitive world. Scoring good performance also could help them feel confident to establish their career pathway, because undergraduates feel uncertain about how their academic qualifications lead to their profession [3].

\section{Limitations}

This study has proven that intrapreneurial self-capital plays a role as a mediator between the satisfaction of life, academic performance, and flourishing. However, the result is confined to 
undergraduates from one public university in Sabah, Malaysia. It is recommended to expand the sample size and geographical range to generalize the study for undergraduates in Malaysia. Future research also could consider interviewing the undergraduates for an in-depth understanding. The collected data were performed at one specific time. The disadvantage for that is undergraduates may receive different scores for different examinations and assignments that could affect their flourishing. A longitudinal study could remedy the disadvantage.

\section{Implications for Practice}

Academicians could infuse intrapreneurial self-capital especially to enhance undergraduates' flourishing academy. Projects and assignments should incorporate innovative and creative structures. At the same time, identified undergraduates that have less intrapreneurial self-capital value during this process should be supported before they join the world of work. Nourishing positive psychology during studying life trains undergraduates to sustain a harsh environment. A lack of intrapreneurial self-capital could foresee undergraduates experience difficulty during employment.

Parents should be aware of the importance to provide a quality living environment for their children. Constant contact should be continued especially when children are bound to leave home for university life. Doing so could help the children to grow and develop with the necessary social skills in a new environment. Undergraduates could consider taking their academic results into account. Acquiring good scores not only creates a bright future in terms of career but also helps increase their positive psychology for a successful life. Undergraduates are encouraged to seize a chance to improve their skills and knowledge during their studying life.

\section{Conclusions}

In conclusion, intrapreneurial self-capital is essential for undergraduates to acquire a flourishing life [31]. Undergraduates that are satisfied with their life could work under pressure and produce innovative ideas. Those university students that show deficiencies on the intrapreneurial self-capital may be at risk to encounter hardship during university life. Securing a place in a university known as a knowledge hub is not sufficient if individuals perceive their life satisfaction does not meet the desired standard. That could affect their psychology resources such as resilience, competence, confidence, and social skills that necessary for work and life sustainability. The results of the present study supported that ISC is a core individual resource to effectively cope and promote the well-being and flourishing of university students in these challenging times [9]. Therefore, the remarkable contribution of this study is intrapreneurial self-capital is deemed fit to be used as the intervention of undergraduates' flourishing life in Eastern countries.

Author Contributions: Conceptualization, P.L.C., and R.I.; Methodology, C.B.S.; Software, C.B.S.; Validation, C.B.S.; Formal Analysis, C.B.S.; Investigation, all the authors; Resources, all the authors; Data Collection, all the authors; Writing-Original Draft Preparation, all the authors; Writing-Review \& Editing, all the authors; Visualization, C.B.S. and P.L.C; Supervision, R.I.; Project Administration, C.B.S.; Funding Acquisition, R.I. All authors have read and agreed to the published version of the manuscript.

Funding: This research received no external funding.

Conflicts of Interest: The authors declare no conflict of interest.

\section{References}

1. Patton, C.M. Changes: A Conflict Management Model for Organizational Redesign Efforts. J. Confl. Manag. 2018, 6, 26-40. Available online: pdfs.semanticscholar.org4f56/4b2888117c80e3102db2ec5274bd9ae78d47.pdf (accessed on 22 June 2019).

2. Blustein, D.L.; Kenny, M.E.; Di Fabio, A.; Guichard, J. Expanding the Impact of the Psychology of Working: Engaging Psychology in the Struggle for Decent Work and Human Rights. J. Career Assess. 2019, 27, 3-28. [CrossRef] 
3. Peiró, J.M.; Sora, B.; Caballer, A. Job Insecurity in The Younger Spanish Workforce: Causes and Consequences. J. Vocat. Behav. 2012, 80, 444-453. [CrossRef]

4. Mcilveen, P.; Di Fabio, A. Intrapreneurial Self-Capital training: A Case Study of an Italian University Student. In Narrative Interventions in Post-Modern Guidance and Career Counseling; Di Fabio, A., Bernaud, J.L., Eds.; Springer Nature: Basel, Switzerland, 2018; pp. 197-209.

5. Malik, M.; Nordin, N.; Zakaria, A.; Sirun, N. An Exploratory Study on the Relationship between Life Satisfaction and Academic Performance among Undergraduate Students of UiTM, Shah Alam. Procedia Soc. Behav. Sci. 2013, 90, 334-339. [CrossRef]

6. Di Fabio, A.; Van Esbroeck, R. Intrapreneurial Self-Capital: A Concept Fitting A Life-Designing Intervention. Couns. G. Ital. Ric. Appl. 2016, 9. [CrossRef]

7. Di Fabio, A. Intrapreneurial Self-Capital: A New Construct for the 21st Century. J. Employ. Couns. 2014, 51, 98-111. [CrossRef]

8. Di Fabio, A.; Saklofske, D.H. The Contributions of Personality Traits and Emotional Intelligence to Intrapreneurial Self-Capital: Key Resources for Sustainability and Sustainable Development. Sustainability 2019, 11, 1240. [CrossRef]

9. Di Fabio, A.; Kenny, M.E. Intrapreneurial Self-Capital: A Key Resource for Promoting Well-Being in a Shifting Work Landscape. Sustainability 2018, 10, 3035. [CrossRef]

10. Huppert, F.A.; So, T.T.C. Flourishing Across Europe: Application of a New Conceptual Framework for Defining Well-Being. Soc. Indic. Res. 2013, 110, 837-861. [CrossRef]

11. Diener, E.; Wirtz, D.; Tov, W.; Kim-Prieto, C.; Choi, D.W.; Oishi, S.; Biswas-Diener, R. New Well-Being Measures: Short Scales to Assess Flourishing and Positive and Negative Feelings. Soc. Indic. Res. 2010, 97, 143-156. [CrossRef]

12. Diener, E.; Seligman, M.E. Very Happy People. Psychol. Sci. 2002, 13, 81-84. [CrossRef]

13. Yun, Y.H.; Rhee, Y.E.; Kang, E.; Sim, J. The Satisfaction with Life Scale and the Subjective Well-Being Inventory in the General Korean Population: Psychometric Properties and Normative Data. Int. J. Environ. Res. Public Health 2019, 16, 1538. [CrossRef]

14. Ho, M.Y.; Cheung, F.M.; Cheung, S.F. The Role of Meaning in Life and Optimism in Promoting Well-Being. Personal. Individ. Differ. 2010, 48, 658-663. [CrossRef]

15. Kong, F.; Ding, K.; Zhao, J. The Relationships among Gratitude, Self-esteem, Social Support and Life Satisfaction among Undergraduate Students. J. Happiness Stud. 2014, 16, 477-489. [CrossRef]

16. Antaramian, S. The Importance of Very High Life Satisfaction for Students' Academic Success. Cogent Educ. 2017, 4. [CrossRef]

17. Datu, J.A.D. Flourishing is Associated with Higher Academic Achievement and Engagement in Filipino Undergraduate and High School Students. J. Happiness Stud. 2018, 19, 27-39. [CrossRef]

18. Huang, G.H.C.; Gove, M. Confucianism, Chinese Families, and Academic Achievement: Exploring How Confucianism and Asian Descendant Parenting Practices Influence Children's Academic Achievement. Sci. Educ. East Asia 2015, 41-66. [CrossRef]

19. Huppert, F.A. Psychological Well-Being: Evidence Regarding Its Causes and Consequences. Appl. Psychol. Health Well-Being 2009, 1, 137-164. [CrossRef]

20. Di Fabio, A.; Palazzeschi, L.; Bucci, O. In an Unpredictable and Changing Environment: Intrapreneurial Self-Capital as a Key Resource for Life Satisfaction and Flourishing. Front. Psychol. 2017, 8, 1819. [CrossRef]

21. Judge, T.A.; Erez, A.; Bono, J.E.; Thoresen, C.J. The Core Self-Evaluations Scale: Development of a Measure. Pers. Psychol. 2003, 56, 303-331. [CrossRef]

22. Maddi, S.R. Issues and interventions in stress mastery. In Personality and Disease; Wiley: New York, NY, USA, 1990; pp. 121-154.

23. Luthar, S.S.; Cicchetti, D.; Becker, B. The Construct of Resilience: A Critical Evaluation and Guidelines for Future Work. Child Dev. 2000, 71, 543-562. Available online: www.ncbi.nlm.nih.gov/pmc/articles/ PMC1885202/pdf/nihms-21559.pdf (accessed on 22 June 2019). [CrossRef]

24. Midgley, C.; Maehr, M.L.; Hruda, L.Z.; Anderman, E.; Anderman, L.; Freeman, K.E.; Urdan, T. Manual for the Patterns of Adaptive Learning Scales; University of Michigan: Ann Arbor, MI, USA, 2000.

25. Frost, R.O.; Shows, D.L. The Nature and Measurement of Compulsive Indecisiveness. Behav. Res. Ther. 1993, 31, 683-692. [CrossRef] 
26. Mann, L.; Burnett, P.; Radford, M.; Ford, S. The Melbourne Decision Making Questionnaire: An Instrument for Measuring Patterns for Coping with Decisional Conflict. J. Behav. Decis. Mak. 1997, 10, 1-19. [CrossRef]

27. Di Fabio, A.; Gori, A. Neuroticism and Flourishing in White Collar Workers. In Neuroticism; Di Fabio, A., Ed.; Nova Sciences Publisher: New York, NY, USA, 2016; pp. 129-146.

28. Puigmitja, I.; Robledo, E.; Topa, G. Cross-Cultural Validity and Psychometric Properties of the ISC Intrapreneurial Self-Capital Scale in Spain. Personal. Individ. Differ. 2019, 151. [CrossRef]

29. Bee Seok, C.; Hamid, A.; Shah, H.; Ismail, R. Psychometric Properties of the Intrapreneurial Self-Capital Scale in Malaysian University Students. Sustainability 2019, 11, 881. [CrossRef]

30. Pavot, W.; Diener, E. The Satisfaction with Life Scale and the Emerging Cnstruct of Life Satisfaction. J. Posit. Psychol. 2008, 3, 137-152. [CrossRef]

31. Duradoni, M.; Di Fabio, A. Intrapreneurial Self-Capital: A Primary Preventive Resource for 21st-Century Entrepreneurial Contexts. Front. Psychol. 2019, 10, 1060. [CrossRef]

(C) 2020 by the authors. Licensee MDPI, Basel, Switzerland. This article is an open access article distributed under the terms and conditions of the Creative Commons Attribution (CC BY) license (http://creativecommons.org/licenses/by/4.0/). 